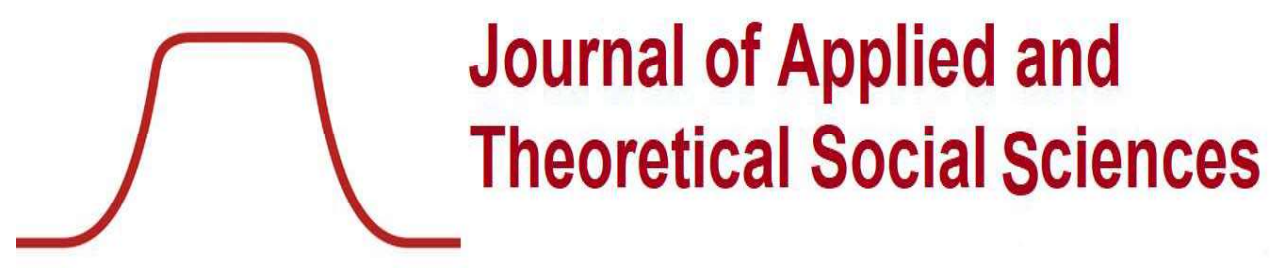

ICCSOR

JATSS, 2021; 3(1), 50-68

$\underline{\text { Research Article }}$

The Relationship Between Inflation, Budget Deficit and Tax Revenues: The Case of Turkey ${ }^{\mathrm{a}}$

\section{Muhammed ÇAM ${ }^{\mathrm{b}}$}

Yusuf TEMÜR
ISSN:2687-5861

First Submission

:Feb.2, 2021

Revised Submission After Review : Mar.11, 2021

Accepted For Publication

:Mar.31, 2021

Available Online Since

:Mar.31, 2021

\begin{abstract}
Nowadays, budget deficits and inflation are among the most important macroeconomic problems of countries. It is also thought that tax revenues, which constitute a source of public service provision, should be analyzed in the context of inflation and budget deficits. For this purpose, the relationship between inflation, budget deficits and tax revenues has been tried to be determined. In this context, impulse response analysis and variance decomposition calculation based on VAR model were used. The study is based on monthly time series analysis for the period 2000-2018. The mentioned data set was obtained from the Central Bank's EVDS data bank. As a result, it has been determined that there is a mutual interaction between inflation, tax revenues and budget deficits.
\end{abstract}

Keywords- Budget Deficits, Inflation, Tax Revenues.

Jel Codes: E31, H68, C23

a The article has been produced from the first author's master's thesis.

b SGK Controller.m.cam1994@hotmail.com.

c Assoc.Prof.Dr, Researcher and Writer. yusuf.temur@gop.edu.tr 


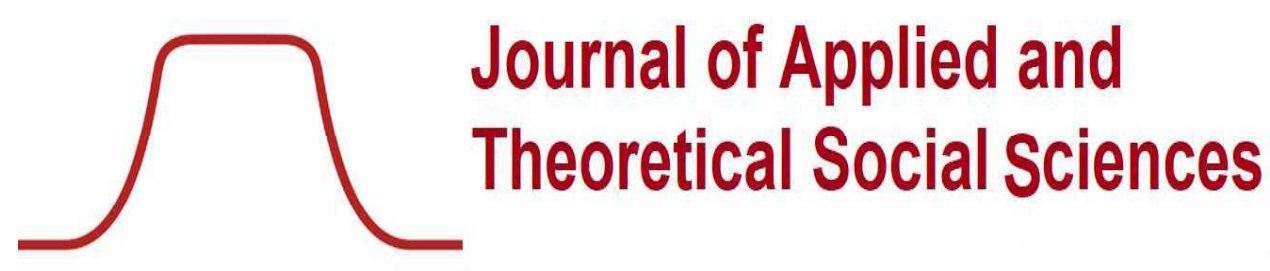

ICCSOR

JATSS, 2021; 3(1), 50-68

Arasturma Makalesi
ISSN:2687-5861

İlk Başvuru

:2 Şubat 2021

Düzeltilmiş Makalenin Alınışı: 11 Mart 2021

Yayın İçin Kabul Tarihi

:31 Mart 2021

Online Yayın Tarihi

\title{
Enflasyon, Bütçe Açığı ve Vergi Gelirleri İlişkisi: Türkiye Örneği ${ }^{a}$
}

\author{
Muhammed ÇAM \\ Yusuf TEMÜR
}

Öz

Günümüzde bütçe açıkları ve enflasyon olgusu ülkelerin oldukça önemli makroekonomik sorunları arasındadır. Ayrıca kamusal hizmet sunumunda kaynak teşkil eden vergi gelirlerinin de enflasyon ve bütçe açıkları bağlamında incelenmesi gerektiği düşünülmektedir. $\mathrm{Bu}$ amaçla çalışmada enflasyon, bütçe açıları ve vergi gelirleri arasındaki ilişki belirlenmeye çalışılmıştır. Bu bağlamda VAR modeline dayalı, etki tepki analizi ve varyans ayrıştırma hesaplamasından yararlanılmıştır. Çalışma 2000-2018 dönemine ait aylık zaman serisi analizine dayanmaktadır. Söz konusu veri seti Merkez Bankası EVDS veri bankasından sağlanmıştır. Sonuç olarak enflasyon, vergi gelirleri ve bütçe açıkları arasında karşl1ıklı bir etkileşim olduğu belirlenmiştir.

Anahtar Kelimeler: Bütçe Açıkları, Enflasyon, Vergi Gelirleri.

Jel Kodlari: E31, H68, C23

a Makale, birinci yazarın yüksek lisans tezinden üretilmiştir.

bSGK Denetmeni.m.cam1994@hotmail.com.

c Doç.Dr, Araştırmacı ve Yazar. yusuf.temur@gop.edu.tr 


\section{Giriş}

Günümüz toplumlarında toplu yaşamın zorunlu kıldığı ihtiyaçlar giderek artmaktadır. Kamusal ihtiyaçların karşılanmasında devletlere düşen görev ve yükümlülükler de bu durumla orantılı olarak artış göstermektedir. Bu paralelde, devlet biryandan artan kamusal ihtiyaçları karşılama çabasını ortaya koyarken öte yandan ortaya çıkması muhtemel sosyoekonomik sorunları da göz önünde tutmalıdır.

Kamusal ihtiyaçların karşılanması finansman boyutu ile birlikte düşünüldüğünde, kamu gelirleri ile kamu giderlerinin kayda alındığı bütçe gerçeği ile karşılaşılır. Bütçe basit ifade şekliyle; devlete kamu harcaması yapma ve kamu gelirlerini toplama yetkisi veren kanuni bir düzenlemedir (Erdem ve Diğerleri, 2012:287). Bu yasal düzenlemede tahmini kamu harcamalarının büyüklüğü buna eşdeğer bir kamu geliri zorunluluğunu ortaya koymaktadır (Edizdoğan ve Çetinkaya, 2019:2). Söz konusu kamu gelirleri içinde vergilerin ayrı bir önemi vardır (Şener, 2016:151).

Bütçe uygulamalarında bütçe gider kalemlerinin bütçenin gelir kalemlerinden fazla olması bütçe uygulamalarında bütçe açığı sorununa yol açması nedeniyle istenilen bir durum değildir. Zira Bütçede genellikle giderlere yönelik ödenekler yetersiz kalırken gelir tahminlerine de bir türlü ulaşılamamaktadır (Feyzioğlu, 1999:166). Bütçe açılarının kronik hale gelmesi bir ülkenin makroekonomik dengelerinin bozulmasına ve ekonomik istikrarsızlığa neden olabilir. Bütçe açıklarının, enflasyon oranı, ekonomik büyüme, ödemeler dengesi, yatırımlar ve işgücü gibi temel makroekonomik değişkenler üzerinde farklı düzeylerde çeşitli etkileri vardır (Samirkaş, 2014:203). Bütçe açığ1 söz konusu olduğunda, olumsuz etkileri ortadan kaldırmak için bu tür açıkların finanse edilmesinde çözüm bulmak önemlidir (Patience ve Augustine, 2008:58). Bütçe yönetiminde bütçe açıklarını özellikle makroekonomik sorunlar oluşturduğundan belirli bir seviyede tutulması tercih edilir.

Bütçe açıkları sonucu görülen ilk makroekonomik etki ise, genel olarak enflasyon artışıdır (İpek ve Akar, 2016:168). Bir ekonomide fiyatlar genel düzeyinin sürekli artması olarak nitelenen enflasyon, paranın satın alım gücünün azalması olarak bilinir (Dinler, 2019:474). Enflasyon öncelikle azgelişmiş ve gelişmekte olan ülkelerle birlikte tüm ülkeleri ilgilendiren en önemli sosyoekonomik sorunlar arasındadır. Enflasyon olgusu, teorik açıdan birçok farklı makroekonomik değişkeni etkilemekte ve söz konusu bu değişkenlerden de etkilenmektedir. Bir ekonomide neredeyse tüm kesimleri derinden etkileyen enflasyon olgusunun etkilendiği faktörlerin belirlenmesi uygulanan iktisat politikalarının başarılı olması açısından fazlaca önem taşımaktadır ve iktisat alanında uzun yıllar tartışılagelmektedir (Alper, 2018:800).

Enflasyon çeşitli faktörlerle açıklanabilir. İktisadi düşünce okulları bu bağlamda farklı teoriler sunar. Klasik düşünce okulu enflasyonu parasal genişlemenin bir sonucu olarak ve paranın miktar teorisini bunun bir açıklaması olarak görür. Keynesyen düşünce, fiyat düzeyindeki değişiklikleri açılamada en önemli faktörün talep cephesi olduğunu vurgularlar. Monetaristler para arzını enflasyonun tek nedeni olarak görürler. Friedman, bu düşünce okulunun en büyük savunucusudur ve her yerde enflasyonun parasal bir fenomen olduğu kabul edilir. Mali açıklarda kalıcı bir artış olduğu zaman, hükümetlerin en kolay finansman seçimini, bütçe açığını paraya çevirmeyi tercih ettikleri ve bunun sonunda fiyat seviyesini yükselteceği görüşündedir (Ishaq and Mohsin, 2015:180; Eroğlu, 2020:87 ). Bu düşünceye göre enflasyonu azaltmadan önce bütçe açığını önlemek gerekmektedir (Erdil Şahin, 2019:298). Gelişmekte olan ülkelerde enflasyon olgusunu açıklamak ise daha büyük bir öneme sahiptir. Çünkü bu 
ülkeler açısından enflasyon sadece bir istikrarsızlığı değil, kalkınma sürecini de ilgilendiren bir sorunu ifade etmektedir (Ataç, 2016:152).

Bütçe açığının bir ülkenin enflasyon verilerini ve makro ekonomik göstergeleri bozucu önemli sonuçlar doğurduğu yönünde iktisadi çevrelerde önemli tartışmalar yaşanmaktadır (Anusic, 1994:21). Bu tartışmaların bir kısmı, enflasyonun bütçe açıklarına neden olduğu yönünde gerçekleşirken bir kısmı da bütçe açıklarının enflasyonu olumsuz yönde etkilediği yönündedir. Enflasyonist dönemde vergi gelirleri reel olarak azalmakta ve bütçe açıkları artmaktadır (Abdioğlu ve Terzi, 2009:195). Bu çalışma enflasyonun bütçe açıklarına neden olduğu yönündeki tartışmalara katkı yapmayı hedeflemektir.

Bütçe açıklarının tahvil ihracı yoluyla ve bu tahvillerin halka sunumuyla finanse edilmesi parasal tabanı, yani para arzını artırmadığı için enflasyon etkisi yaratmamaktadır. Ancak, bütçe açıklarını finanse ederken ihraç edilen tahviller merkez bankası tarafından satın alındığında ya da para basımıyla finanse edilmesi parasal tabanı ve para arzını artıracağı için enflasyona sebep olmaktadır (Pınar, 2017:77; Eroğlu, 2020:87). Enflasyon ve bütçe açıkları arasındaki ilişkiyi inceleyen çalışmaların başında Olivera (1967) tarafindan kullanılan gecikmeli olarak tahsil edilen vergilerin enflasyon nedeniyle reel olarak azalacağını, bütçe açıklarının artacağını ve dolayısıyla devletin enflasyonla gelir elde etmesinin bir sınırı olduğunu savunan görüş ile Tanzi(1978) tarafından Arjantin ekonomisi için yapılan çalışma gelmektedir. Enflasyon vergi gelirlerini birkaç farklı şekilde etkilemektedir. Enflasyonist bir ekonomide vergi mükellefinin beyana dayalı olarak ödediği gelir vergisi düzeyi, reel değeri açısından azalmaktadır. Zira beyana dayalı vergi gelirleri, verginin tarhı ile tahsili arasındaki sürenin uzunluğundan dolayı enflasyonist bir ortamda vergi gelirlerinde azalma meydana gelir. Beyana tabi gelir vergisinin ödenmesinde oluşan gecikme, enflasyon sebebiyle vergi gelirlerini reel olarak törpülemektedir. Enflasyon düzeyi ne derece yüksek olursa, beyannameye dayalı vergi gelirlerinde o denli bir kayıp ortaya çıkacaktır. (Somel, 2014:174-175).Vergilerle ilgili olarak, verginin toplanmasında ortaya çıkan gecikmeler sorunu ve gelişmekte olan ülkelerde görülen toplam vergi gelirleri içerisinde artan oranlı vergi payının düşüklüğü gibi konular dikkate alındığında, enflasyon oranına bağlı olarak gerçek vergi gelirlerinde bir kayıp olduğu sonucuna ulaşlabilecektir (Özbilen, 1999:278).

Vergi gelirlerinde meydana gelen bir azalma kamu harcamalarının finansman sorununu dolayısıyla bütçe açığını beraberinde getirebilmektedir. Enflasyon oranında artışla birlikte vergi gelirleri Tanzi-Olivera etkisi olarak adlandırılan reel bir azalmayla karşı karşıya gelebilmektedir. Söz konusu durumun kısır bir döngü haline gelmesi ekonomik sorunları kronik hale getirebilmekte ve sorunların çözümünü zorlaştırabilmektedir. $\mathrm{Bu}$ amaçla çalışma Türkiye'de enflasyon, vergi gelirleri ve bütçe açığı arasındaki ilişkiyi incelenmiştir. İki bölümden oluşan çalışmada birinci bölümde kavramsal çerçeve ve ilgili literatür çalışmaları ele alınırken ikinci bölümde Türkiye'ye ait veriler kullanılarak olgular arası ampirik analize yer verilmiştir.

\section{Literatür}

Toplumların refahının artırılmasında ve toplumsal sorunların çözümünde bilimsel anlamda teorik ve ampirik çalışmalar ilgili kişi ve kuruluşlara yol gösterici olmaktadır. $\mathrm{Bu}$ minvalde bütçe açıkları ve enflasyon gibi ekonomik sorunları açıklamak üzere literatürde birçok çalışma mevcuttur. Bu çalışmalarda enflasyon ve bütçe açıkları arasında ilişki olup/olmadığı ele alınırken farklı dönemler, analiz yöntemleri, değişkenler ve veri setleri kullanılmıştır. İlgili literatür çok geniş olmakla birlikte bazı çalışmalar tabloda belirtilmiştir. 


\begin{tabular}{|c|c|c|c|}
\hline YAZAR(LAR) & DÖNEM & YÖNTEM & SONUC \\
\hline $\begin{array}{l}\text { Solomon ve Met } \\
\text { (2004) }\end{array}$ & $1967-2001$ & Eşbütünleşme Analizi & $\begin{array}{l}\text { Bütçe açığının monetizasyonu nedeniyle } \\
\text { bütçe açığındaki artışlarda önemli } \\
\text { enflasyonist etkiler bulunmuştur. }\end{array}$ \\
\hline Lozano (2008) & $\begin{array}{l}1982: 1- \\
2007: 4\end{array}$ & $\begin{array}{l}\text { Vektör Hata Düzeltme } \\
\text { Modeli }\end{array}$ & $\begin{array}{l}\text { Çalışmada, bir yandan enflasyon ile para } \\
\text { büyümesi arasında, diğer yandan da para } \\
\text { büyümesi ile bütçe açığı arasında yakın bir } \\
\text { ilişki bulunmuștur. }\end{array}$ \\
\hline Oktayer (2010) & $1987-2009$ & $\begin{array}{l}\text { Johansen Eşbütünleşme } \\
\text { Testi }\end{array}$ & $\begin{array}{l}\text { Uzun dönemde bütçe açı̆̆ındaki artışların } \\
\text { enflasyonu arttırdığı sonucuna ulașilmıștır. }\end{array}$ \\
\hline $\begin{array}{l}\text { Zonuzi ve } \\
\text { Diğerleri (2010) }\end{array}$ & $\begin{array}{l}1990: 1- \\
2007: 4\end{array}$ & $\begin{array}{l}\text { Çoklu kırılma testi, } \\
\text { Birim kök testi }\end{array}$ & $\begin{array}{l}\text { Bütçe açığı ve enflasyon arasında olumlu } \\
\text { ve anlamlı bir iliş̧ki bulunmuştur. }\end{array}$ \\
\hline Rosa (2011) & 1954-1995 & Johansen Metodu & $\begin{array}{l}\text { GSYH'nin yüzdesi olarak bütçe açığ ve ve } \\
\text { enflasyon arasında anlamlı bir ilişki } \\
\text { bulunamamıştır. }\end{array}$ \\
\hline $\begin{array}{l}\text { Georgantopoulos } \\
\text { ve Tsamis (2011) }\end{array}$ & 1980-2009 & $\begin{array}{l}\text { Varyans Hata Düzeltme } \\
\text { Modeli }\end{array}$ & $\begin{array}{l}\text { Bütçe açığı ile enflasyon arasında anlamlı } \\
\text { bir bağlantı bulunamamıştır. }\end{array}$ \\
\hline $\begin{array}{l}\text { Sağlam ve Uğurlu } \\
\text { (2013) }\end{array}$ & $1983-2008$ & $\begin{array}{l}\text { Sinır Testi } \\
\text { Var Analizi }\end{array}$ & $\begin{array}{l}\text { Kısa dönemde para arzındaki artı̧ların } \\
\text { enflasyonu arttırdığı kamu kesimi borçlanma } \\
\text { gereksinimindeki artışın para arzını artırıdığı, } \\
\text { enflasyonu ise azalttığı sonucuna ulașılmıștır }\end{array}$ \\
\hline $\begin{array}{l}\text { Bayrak ve Kanca } \\
\text { (2013) }\end{array}$ & $1980-2011$ & $\begin{array}{l}\text { Johansen Eşbütünleşme } \\
\text { testi, } \\
\text { Granger Nedensellik } \\
\text { testi, } \\
\text { Koentegrasyon analizi, } \\
\text { ADF testi }\end{array}$ & $\begin{array}{l}\text { Bütçe açıkları ve enflasyon arasında kısa ve } \\
\text { uzun dönemde pozitif ve anlamlı bir iliş̧kinin } \\
\text { olduğunu ve bütçe açılarındaki artışın } \\
\text { enflasyonu olumsuz yönde etkilediğini } \\
\text { göstermektedir. }\end{array}$ \\
\hline $\begin{array}{l}\text { Bedir ve Tural } \\
(2014)\end{array}$ & $1970-2010$ & ARDL sinır testi & $\begin{array}{l}\text { Bütçe açıları ile enflasyon arasında hem } \\
\text { kısa hem de uzun dönemli pozitif bir ilişki } \\
\text { olduğu sonucu bulunmuştur. }\end{array}$ \\
\hline $\begin{array}{l}\text { Erkam ve } \\
\text { Çetinkaya (2014) }\end{array}$ & $\begin{array}{l}\text { 1987:M1- } \\
\text { 2003:M6 ve } \\
\text { 2005:M1- } \\
\text { 2013:M6 }\end{array}$ & Granger nedensellik testi & $\begin{array}{l}\text { Yüksek enflasyon döneminde bütçe } \\
\text { açıklarından enflasyona doğru pozitif anlamlı } \\
\text { bir ilişki tespit edilmiştir. }\end{array}$ \\
\hline $\begin{array}{l}\text { Tiwari ve } \\
\text { Diğerleri (2015) }\end{array}$ & $1990-2013$ & $\begin{array}{l}\text { Granger } \quad \text { Nedensellik } \\
\text { Analizi }\end{array}$ & $\begin{array}{l}\text { Bütçe açı̆̆ ile enflasyon arasında bir ilişki } \\
\text { bulunamamıştır. }\end{array}$ \\
\hline Alper (2016) & $1971-2016$ & $\begin{array}{l}\text { Bayer-Hanck } \\
\text { eşbütünleşme Analizi }\end{array}$ & 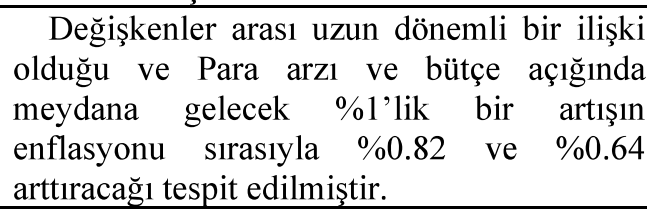 \\
\hline $\begin{array}{l}\text { Akar ve İpek } \\
(2016)\end{array}$ & $\begin{array}{l}2004: 1- \\
2015: 2\end{array}$ & $\begin{array}{l}\text { ARDL analizi, } \\
\text { Toda-Yamamoto } \\
\text { nedensellik analizi }\end{array}$ & $\begin{array}{l}\text { Bütçe açıklarının enflasyonu hem kısa hem } \\
\text { de uzun dönemde artırıcı etkilerinin olduğunu } \\
\text { ortaya koymaktadır. }\end{array}$ \\
\hline $\begin{array}{lll}\text { Kaya } & \text { ve } & \text { Öz } \\
(2016) & & \end{array}$ & $1980-2014$ & ARDL sinır testi & $\begin{array}{l}\text { Enflasyon ile bütçe açı̆̆ arasında uzun } \\
\text { dönemde herhangi bir ilişki olmadığı ancak } \\
\text { kısa dönemde bütçe açığı ile enflasyon } \\
\text { arasında pozitif bir ilişkinin olduğu sonucu } \\
\text { bulunmuştur. }\end{array}$ \\
\hline Oruç (2016) & $1950-2014$ & $\begin{array}{l}\text { Birim kök testi, } \\
\text { En küçük kareler } \\
\text { yöntemi, } \\
\text { Philipis-Oualiris metodu }\end{array}$ & $\begin{array}{llll}\text { Bütçe } & \text { açı̆̆ındaki } & \text { artışların } & \text { enflasyonu } \\
\text { kuvvetli } & \text { bir } & \text { şekilde } & \text { etkilediği } \\
\text { gözlemlenmiştir. } & & \end{array}$ \\
\hline Altunöz (2018) & $0-2016^{200}$ & $\begin{array}{l}\text { ARDL Sinır Testi, } \\
\text { Toda Yamamoto ve } \\
\text { Hisao nedensellik analizi }\end{array}$ & $\begin{array}{l}\text { Olivera Tanzi etkisinin Türkiye ekonomisi } \\
\text { için geçerli olduğu saptanarak, Patinkin } \\
\text { etkisinin varlığ tespit edilmemiştir. }\end{array}$ \\
\hline
\end{tabular}




\begin{tabular}{|c|c|c|c|}
\hline Erdil Şahin (2019) & $1980-2017$ & ARDL Sınır testi & $\begin{array}{l}\text { Bütçe açı̆̆ ve enflasyon arasında uzun ve } \\
\text { kısa dönemde pozitif ve anlamlı bir ilişki } \\
\text { tespit edilmiştir. }\end{array}$ \\
\hline $\begin{array}{ll}\text { Chukwuani } & \text { ve } \\
\text { Egiyi (2020) } & \end{array}$ & 2019 & $\begin{array}{l}\text { Dickey Fuller testi, } \\
\text { Granger nedensellik testi }\end{array}$ & 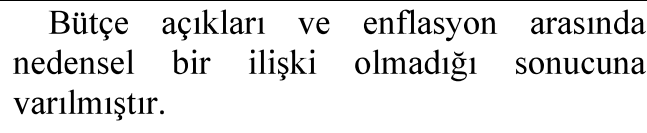 \\
\hline $\begin{array}{lr}\text { Bayır } & \text { ve } \\
\text { Güvenoğlu }(2020)\end{array}$ & 2009-2019 & $\begin{array}{ll}\text { Granger } & \text { nedensellik } \\
\text { analizi }\end{array}$ & $\begin{array}{l}\text { Para arzı ve bütçe açı̆̆ından enflasyona } \\
\text { doğru tek yönlü nedensellik tespit edilmiştir. }\end{array}$ \\
\hline Çavuşoğlu (2005) & $1987-2003$ & $\begin{array}{l}\text { Johansen Eşbütünleşme } \\
\text { testi, }\end{array}$ & $\begin{array}{l}\text { Enflasyon, reel vergi gelirleri, reel kamu } \\
\text { harcamaları ve reel gelir düzeyi ilişkileri test } \\
\text { edilmiştir Yüksek enflasyon hem vergi } \\
\text { gelirlerinin hem de kamu harcamalarının reel } \\
\text { değerini azaltıcı etkilere sahiptir. Patinkin } \\
\text { etkisi Tanzi etkisinden daha büyüktür ve bu } \\
\text { da enflasyonun bütçe açıklarının reel yükünü } \\
\text { hafifletici bir role sahip olduğunu sonucuna } \\
\text { varılmıştır. }\end{array}$ \\
\hline Beşer (2007) & $1987-2005$ & Boostrap VAR Modeli & $\begin{array}{l}\text { Tanzi etkisi hem cari dönem için hem de } \\
\text { parasal genişlemenin enden olduğu uzun } \\
\text { dönem için reel vergi gelirlerini } \\
\text { aşındırmaktadır. Tanzi etkisi istatiksel } \\
\text { olarak anlamlı ve oldukça kuvvetlidir. }\end{array}$ \\
\hline $\begin{array}{l}\text { Erdoğan ve } \\
\text { Erdoğan (2018) }\end{array}$ & $2007-2016$ & $\begin{array}{lll}\text { VAR Yöntemi } & \text { ve } \\
\text { Granger } & & \\
\text { Nedensellik Testi } & \end{array}$ & $\begin{array}{l}\text { Kısa dönemde enflasyonun harcamalar ve } \\
\text { vergi gelirleri üzerinde reel bir etkisi } \\
\text { bulunmadığı sonucuna ulaşıllırken; uzun } \\
\text { dönemde Tanzi ve Patinkin etkileri geçerlidir. } \\
\text { Nedensellik açısından ise, kamu harcamaları } \\
\text { ile vergi gelirleri, enflasyon ile karşıllıklı iki } \\
\text { yönlü ilişkili olduğu sonucuna ulaşılmıștır }\end{array}$ \\
\hline
\end{tabular}

\section{Metodoloji, Yöntem ve Bulgular}

Çalışmada enflasyon, bütçe açıkları ve vergi gelirleri arasındaki ilişkinin belirlenmesinde zaman serileri kullanılmıştır. Bu amaca uygun olarak VAR modeline dayalı, etki tepki analizi ve varyans ayrıștırma hesaplamasından yararlanılmıştır. VAR modelinin seçilmesinin ana nedeni bu modelin literatüre göre makroekonomik çalışmalarda en etkili model olarak kabul edilmesinden dolayıdır. Çünkü ekonomik değişkenler arasındaki dinamik ilişkileri yakalamak için oldukça etkili bir yöntemdir (Kazdagll, 1996:42). Makroekonomik modellerde kullanılan değişkenlerin dışsal olup olmadığının kesin olarak bilinmediği durumlarda VAR modelleri kullanılmaktadır. Sims tarafından geliştirilen VAR modeli, seçilen bütün değişkenleri birlikte ele alan bir sistem bütünlüğü içerisinde incelemektedir. Makroekonomik modellerde yer alan değişkenler arasında genellikle dinamik bir geri besleme mevcuttur. Sistemde yer alan herhangi bir zaman serisinin, zaman içinde izlediği trendin, sistemdeki başka bir zaman serisinin trendinden bağımsız olup olmadığı tam olarak bilinememektedir. Bu tür simetrik bir etkileşimin söz konusu olduğu zaman serilerini içeren çok dcnklemli sistemlerde, VAR adı verilen yöntemler kullanılmaktadır. VAR modelinin önemli bir özelliği, teorinin öngördüğü nedensellikten ziyade değişkenler arası gerçek nedensellik ilişkilerini ortaya koymasıdır (Özgen ve Güloğlu, 2004, s.101-13).

\subsection{Veri Seti ve Yöntem}

Bu çalışma 2000-2018 dönemine ait aylık zaman serisi analizine dayanmaktadır. Söz konusu zaman serisi analizinde kullanılan veri seti Merkez Bankası EVDS veri bankasından elde edilmiştir. Bu çalışmada örtülü bir amaç olarak enflasyon bağımlı değişken, bütçe açığg ve 
vergi gelirleri bağımsız değişkenler olarak kabul edilerek söz konusu bağımsız değişkenlerin bağımlı değişken üzerindeki etkileri analiz edilmiştir. Bu amaca uygun biçimde analiz fonksiyonu şu biçimdedir: Inf = $\mathrm{f}(\mathrm{BD}, \mathrm{TAX})$.Burada; Inf: aylık enflasyon oranlarını, BD: Aylık bütçe açığını ve TAX: aylık vergi gelirlerini simgelemektedir. Çalışmaya ait veri setinin tanımlayıcı istatistikleri ise Tablo 1'de gösterilmiştir.

Jargue Bera (JB) test istatistiği serilerin normal dağılıp dağılmadığını göstermektedir. JB istatistiğinde null (sıfır) hipotezi serilerin normal dağılmadığı biçimindedir. Tablo 1'de görüldüğü gibi her üç seri içinde olasılık değeri \% 1 anlamlılık düzeyinde null hipotezin reddine işaret etmektedir. Buna göre her üç seri de yani Inf, BD ve TAX normal dağılım göstermektedir.

Bundan sonraki aşama serilerin durağanlık sınamalarıyla ilgilidir. Ekonometrik çalışmalarda ele alınan serilerin durağan olmaları beklenir. Çünkü durağan olmayan zaman serileriyle yapılacak sınamalar sahte bulgular elde edilmesine yol açabilecektir. Bu çalışmada serilerin durağanlık sinamaları ADF (Agumented Dicky and Fuller) ve PP (Phillps ve Perron) testlerine göre yapılmış ve Tablo 2'de gösterilmiştir. 


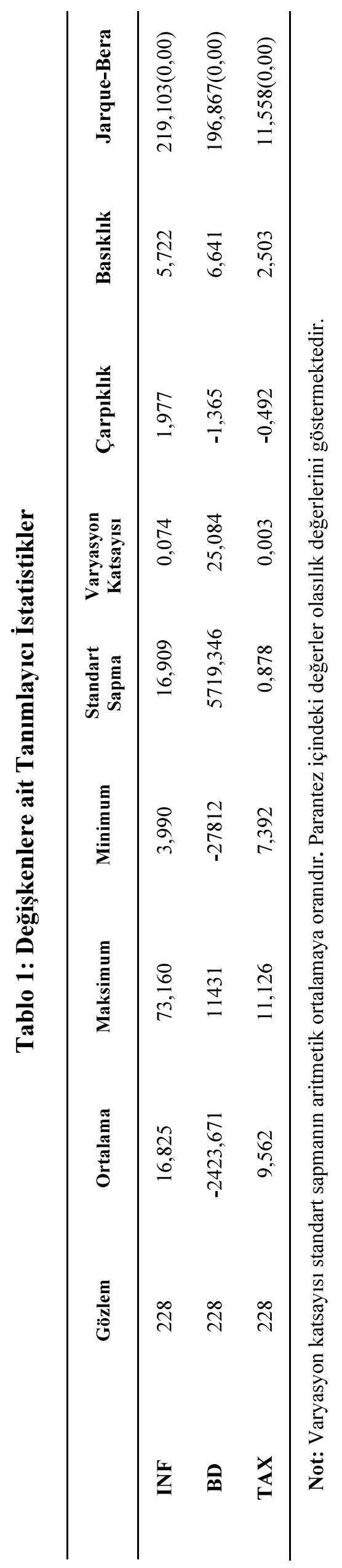

in 
Yukarıda da belirtildiği gibi modeli oluştururken değişkenler arasındaki dinamik ilişkileri görmek amacıyla, VAR modelinde değişkenlerin durağan oldukları seviyeleri bulmak gerekmektedir. Bu amaçla ekonometri literatüründe Dickey-Fuller (1981, ADF) ve PhillipsPerron $(1988$, PP) tarafından geliştirilen yapısal kırılmaları dikkate almayan doğrusal birim kök testleri yapılmıştır.

Tablo 2: ADF (1981) ve PP (1988) Birim Kök testi Sonuçları

\begin{tabular}{|c|c|c|c|c|c|c|c|c|}
\hline \multirow{4}{*}{ בे. } & & Değgiskenler & ADF & PP & \multirow{4}{*}{ 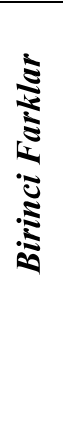 } & Değgiskenler & ADF & PP \\
\hline & \multirow{3}{*}{ Sabit } & INF1 & $\begin{array}{c}- \\
2.03(13) \\
{[0.27]}\end{array}$ & $\begin{array}{l}-3,11(7) \\
{[0.02]^{* *}}\end{array}$ & & INF1 & $\begin{array}{l}-5,66(12) \\
{[0.00]^{* * *}}\end{array}$ & $\begin{array}{l}-7,52(6) \\
{[0.00]^{* * *}}\end{array}$ \\
\hline & & BD & $\begin{array}{c}-1,74 \\
(11) \\
{[0.40]}\end{array}$ & $\begin{array}{c}20.88(7) \\
{[0.00]^{* * *}}\end{array}$ & & BD & $\begin{array}{c}-10,30(10) \\
{[0.00]^{* * *}}\end{array}$ & $\begin{array}{c}-183,69(85) \\
{[0.00]^{* * *}}\end{array}$ \\
\hline & & TAX & $\begin{array}{c}-3,46 \\
(13) \\
{[0,01]^{* *}} \\
*\end{array}$ & $\begin{array}{l}-2,18 \\
(21) \\
{[0,21]}\end{array}$ & & TAX & $\begin{array}{l}-3,84(12) \\
{[0,00]^{* * *}}\end{array}$ & $\begin{array}{c}-66,66(169) \\
{[0,00]^{* * *}}\end{array}$ \\
\hline
\end{tabular}

Not: $* * * * *$ ve $*$ değerleri sirasıyla $\% 1 . \% 5$ ve $\% 10$ anlam seviyelerinde serilerin durağanlıklarını göstermektedir. Parantez içindeki değerler Schawarz bilgi kriterine göre optimal gecikme uzunluğunu göstermektedir. Köșeli parantez içindeki değerler olasılık değerlerini göstermektedir.

$\mathrm{ADF}$ ve PP test sonuçlarına göre değişkenlerin tamamı aynı düzeyde durağan olmadıkları görülmektedir. Bu durumda serilerin birinci sıra farkları alınarak yeniden durağanlık sınaması yapılmıştır. Elde edilen bulgular serilerin tamamının birinci sıra farklarının durağan olduğu biçimindedir.

Durağanlık sınamasından sonra VAR modeline dayalı Varyans Ayrıştırma Hesaplaması ve Etki-Tepki Analizinin yapılabileceği anlaşılmaktadır. Ancak bu analizlere geçmeden önce tüm değişkenler arasında nedensellik analizi yapılmıştır. Söz konusu sınamayı yapabilmek için Block Exonogeneity Wald analizinden yararlanılmıştır.

Tablo 3: VAR Granger Nedensellik/Block Exogeneity Wald Test Bulguları

\begin{tabular}{cccc}
\hline \hline Bağımlı Değişken: DINF & & & \\
\hline \hline Dışlanmış & Chi-sq & df & Prob. \\
\hline \hline DBD & 1.185670 & 5 & 0.9462 \\
DTAX & 2.407630 & 5 & 0.7903 \\
\hline \hline Tüm Değişkenler & 4.782206 & 10 & 0.9052 \\
\hline \hline
\end{tabular}

Bă̆ımlı Değişken: DBD

\begin{tabular}{cccc}
\hline \hline Dışlanmış & Chi-sq & df & Prob. \\
\hline \hline DINF & 3.353433 & 5 & 0.6457 \\
DTAX $^{* * *}$ & 60.67381 & 5 & 0.0000 \\
\hline \hline
\end{tabular}


Bağımlı Değişken: DTAX

\begin{tabular}{cccc}
\hline \hline Dişlanmış & Chi-sq & df & Prob. \\
\hline \hline DINF & 2.706752 & 5 & 0.7451 \\
DBD $^{* * *}$ & 54.57901 & 5 & 0.0000 \\
\hline \hline Tüm Değişkenler*** & 57.96393 & 10 & 0.0000 \\
\hline \hline
\end{tabular}

Not: *** \%1 anlamlılık düzeyini göstermektedir.

Granger Nedensellik/Block Exogeneity Wald Testinde sıfır/null hipotez değișkenler arasında nedensellik yoktur biçimindedir. Tablo 3 bulguları incelendiğinde enflasyon hem bütçe açığı hem de veri gelirleriyle çift yönlü bir nedensellik ilişkisi göstermemektedir. Buna karşın bütçe açı̆̆ı ve vergi gelirleri arasında çift yönlü nedensellik ilişkisinin olduğu tahmin edilmiştir.

Bu bulgular çalışmanın 1 numaralı fonksiyonel ilişkisinin geçerliliğini doğrulamaktadır. Daha açık olarak söz konusu modelde bağımlı değişken enflasyon, bağımsız değişkenler ise bütçe açı̆̆ı ve vergi gelirleri olarak belirlenmelidir. Ayrıca bütçe açığı ve vergi gelirleri arasında görülen çift yönlü nedensellik ilişkisi de ekonomi teorisine uygundur. Buna göre vergi gelirleri elbette bütçe açığını belirlemektedir. Bununla birlikte bütçe açığı kamunun vergi politikasını etkilemekte ve vergi gelirlerini belirlemektedir. Yani bütçe açığının artması vergi oranlarında bir artışa yol açabilmekte ve bir sonraki dönem vergi gelirlerini yükseltici bir etki yapabilmektedir.

Son olarak ele alınan değişkenler arasındaki korelasyon ilişkisi yukarıda ortaya konan nedensellik analizi bulgularıyla desteklenmiştir. Çalışmada ele alınan değişkenlere ait korelasyon ilişkisi de Tablo 4'te gösterilmiştir.

Tablo 4: Değişkenler Arasındaki Korelasyonlar

\begin{tabular}{cccc}
\hline & INF & BD & TAX \\
\hline INF & 1 & & \\
BD & $-0,022(+)$ & 1 & 1 \\
TAX & $-0,721(-)$ & $0,009(-)$
\end{tabular}

Not: Parantez içindeki değerler korelasyon ilişkisinin yönünü göstermektedir.

Korelasyon bulgularına göre bütçe açığı ve enflasyon arasında pozitif, enflasyon ve vergi gelirleri arasında ise negatif bir ilişki vardır. Bütçe açığı ve vergi geliri arasında ise negatif yönlü bir ilişki vardır. Enflasyon ve bütçe açığı arasındaki korelasyon değeri (-0.02) olarak bulunmuştur. Korelasyon değerinin negatif olması bütçe açığının hesaplama biçiminden kaynaklanmaktadır. Bütçe Açığı $=\mathrm{T}-\mathrm{G}$ (Vergi gelirleri-Kamu Harcamaları) olarak hesaplandığında bütçe açığı $\mathrm{G}>\mathrm{T}$ olduğundan negatif (-) değerler almıştır. Dolayısıyla bütçe açığı ve enflasyon ilişkisi negatif katsayı değeri çarp1 negatif bütçe açığ1 değeri olarak hesaplanacağından korelasyon ilişkisinin yönünü pozitiftir. Aynı biçimde bütçe açığı ve vergi gelirleri arasındaki ilişkinin yönü de negatif olarak değerlendirilmelidir. Burada da pozitif katsayı değer (0.09) çarpı negatif bütçe açığı değeri üzerinden hesaplama ilişkinin yönünün negatif olmasını gerektirmektedir. Bu durumlar korelasyon değerlerinin yanında belirtilmiştir. 
Söz konusu bulgular nedensellik ilişkisini yansıtmamaktadır. Ancak enflasyon ve vergi gelirleri arasındaki negatif yönlü korelasyon enflasyonun vergi geliri kaybına yol açtığını ifade eden Tanzi-Olivera etkisi ile uyumludur. Yine bütçe açıkları ve enflasyon arasındaki korelasyon ilişkisinin yönünü pozitif olması bütçe açıklarının enflasyonist olduğu biçimde yorumlanabilir. Her iki bulgu da aşağıda gösterilen VAR modeline dayalı etki tepki analiz bulgularıyla uyumludur ve tahmin tutarlılığı vardır denilebilmektedir.

\subsection{Bulgular}

VAR modeline dayalı varyans ayrıştırma ve etki-tepki analizlerine başlamak için öncelikle modelin gecikme uzunluğunun bulunması gerekmektedir. Bunun için verilerin durağan olduğu birinci farkları alınıp, gecikme uzunluğu Eviews 10 paket programı ile hesaplanmıştır. Veriler aylık olduğu için 6'a kadar gecikme uzunluğunu test edilmiştir. Gecikme uzunluğunun belirlenmesinde LM testinden ve Inverse Roots of AR Characteristic Polynomial (Ters köklerin birim çember içinde olması) testinden yararlanmıştır. Her iki test sonucu Şekil 1 ve Tablo 5'te raporlanmıştır. Şekil 1'de görüldüğü gibi ters köklerin tamamı birim çember içerisindedir. Bu sonuca dayalı olarak modelde durağanlık ile ilgili bir sorun yoktur denilebilir. Ayrıca ters köklerin birim çember içerisinde olması kullanılan modelin istikrarlı olduğu yorumunu yapabilmesine de olanak sağlamaktadır. LM testine göre değişken varyans sorunu yoktur ve gecikme uzunluğu beş olarak alınmıştır. Yani istatistiki olarak anlamlılık düzeyi yüksek ve en düşük parametre değere sahip dönem gecikme uzunluğu olarak alınmıştır.

\section{Şekil 1: AR Karakteristik Ters Polinom Köklerinin Birim Çemberdeki}

\section{Konumları}

Inverse Roots of AR Characteristic Polynomial

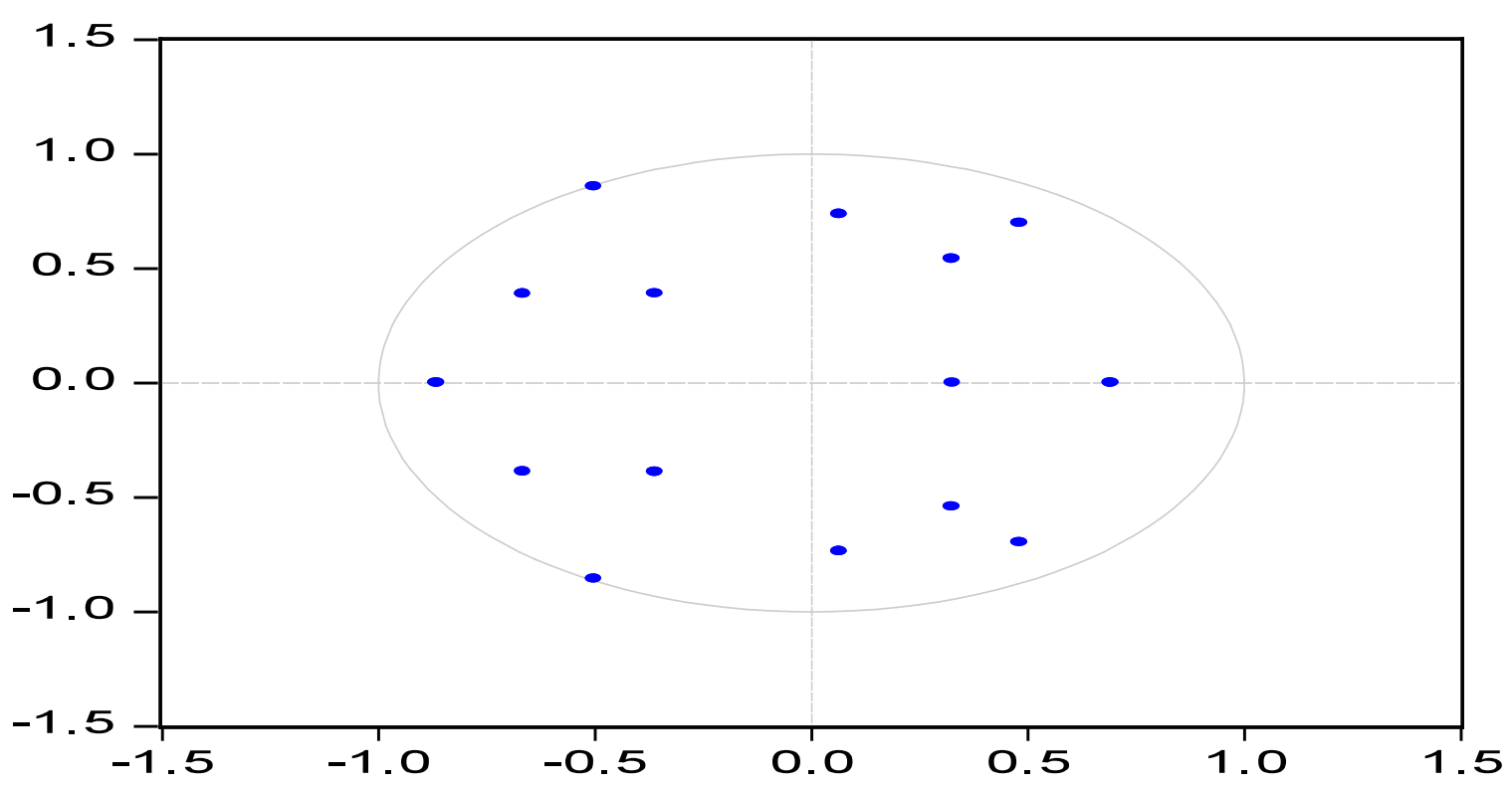


Tablo 5: LM Test Bulguları

\begin{tabular}{ccc}
\hline Lags & LM-Stat & Prob \\
\hline \hline 1 & 12.39403 & 0.1920 \\
2 & 16.36620 & 0.0596 \\
3 & 21.71364 & 0.0098 \\
4 & 8.294416 & 0.5048 \\
$5^{*}$ & 29.61325 & 0.0005 \\
6 & 30.83467 & 0.0003 \\
\hline \hline
\end{tabular}

Not: * seçilmiş gecikme değerini göstermektedir.

Elde edilen sonuçlar modelin 5 gecikme uzunluğunda VAR analizi yapabileceğini göstermektedir. VAR modelleri çalışma açısından en uygun modeldir. Bunun nedeni VAR modellerinde bağımlı bağımsız değişken ayrımı olmayıp tüm değişkenler içsel değişken olarak kabul edilmektedir.

Çalışmada yer alan enflasyon, bütçe açığı ve vergi gelirleri arasında bağımlı bağımsız değişken ayrımının somut olmadığ 1 hem ekonomi literatürüne uygun olarak hem de Tablo 3 ve Tablo 4'te gösterilen nedensellik ve korelasyon analizleriyle ortaya belirlenmiş tüm değișkenlerin birbirini etkileyebileceği görülmüștür.

VAR Modeline dayalı varyans ayrıştırma hesaplaması bütün değişkenleri sıra ile bağımlı değişken olarak ele alıp bağımsız değişken olarak kalan diğer değişkenlerden kaynaklı şokların bağımlı değişkendeki değişmeyi açıklama güçlerinin tahmin edilmesine olanak sağlamaktadır. Yine VAR modeline dayalı etki tepki analizlerinde de benzer biçimde tüm değişkenler sırayla bağımlı değişken olarak ele alınmış ve bağımsız değişkenler kaynaklı şoklara bu bağımlı değişkenin dinamik tepkisi tahmin edilmeye çalışılmıştır.

VAR modeline dayalı her iki analizlerden doğru tahminler alınabilmesi için tüm değişkenlerin aynı düzeyde durağan olması gerekmektedir. Tablo 2'de gösterilen durağanlık sınamaları sonucu tüm değişkenlerin birinci farkları alınarak durağan hale getirilmeleri gerektiğinden VAR analizinde kullanılacak değişkenler birinci farkları alınarak modele eklenmişlerdir.

Çalışmada varyans ayrıştırma hesaplama bulguları Tablo 6' da etki tepki analiz bulguları ise Şekil 2 kümesinde gösterilmiştir.

Tablo 6: Varyans Ayrıştırma Hesaplaması Bulguları

\begin{tabular}{|c|c|c|c|c|}
\hline \multicolumn{5}{|c|}{ Variance Decomposition of DINF: } \\
\hline Period & S.E. & DINF1 & DBD & DTAX \\
\hline 1 & 1.614700 & $\begin{array}{l}100.0000 \\
(0.00000)\end{array}$ & $\begin{array}{l}0.000000 \\
(0.00000)\end{array}$ & $\begin{array}{l}0.000000 \\
(0.00000)\end{array}$ \\
\hline 2 & 1.965408 & $\begin{array}{l}99.46944 \\
(0.81186)\end{array}$ & $\begin{array}{c}0.011935 \\
(0.33073)\end{array}$ & $\begin{array}{c}0.518628 \\
(0.75737)\end{array}$ \\
\hline 3 & 2.026637 & $\begin{array}{l}99.40327 \\
(1.05396)\end{array}$ & $\begin{array}{c}0.014942 \\
(0.64640)\end{array}$ & $\begin{array}{c}0.581785 \\
(0.95631)\end{array}$ \\
\hline 4 & 2.038638 & $\begin{array}{l}99.32485 \\
(1.26748)\end{array}$ & $\begin{array}{c}0.076443 \\
(0.75311)\end{array}$ & $\begin{array}{l}0.598704 \\
(1.07545)\end{array}$ \\
\hline 5 & 2.040741 & $\begin{array}{l}99.15166 \\
(1.61952)\end{array}$ & $\begin{array}{l}0.142470 \\
(0.96217)\end{array}$ & $\begin{array}{c}0.705871 \\
(1.24454)\end{array}$ \\
\hline 6 & 2.042265 & $\begin{array}{l}99.15021 \\
(1.72222)\end{array}$ & $\begin{array}{c}0.144971 \\
(0.99118)\end{array}$ & $\begin{array}{l}0.704819 \\
(1.26350)\end{array}$ \\
\hline
\end{tabular}




\begin{tabular}{|c|c|c|c|c|}
\hline 7 & 2.046384 & $\begin{array}{l}99.08959 \\
(1.77951)\end{array}$ & $\begin{array}{c}0.148994 \\
(0.98375)\end{array}$ & $\begin{array}{c}0.761418 \\
(1.34908)\end{array}$ \\
\hline 8 & 2.049189 & 99.04320 & 0.177184 & 0.779616 \\
\hline & & $(1.81184)$ & $(0.98612)$ & $(1.35395)$ \\
\hline 9 & 2.050503 & 99.01217 & 0.192026 & 0.795804 \\
\hline & & $(1.85867)$ & $(0.99540)$ & $(1.38168)$ \\
\hline 10 & 2.050741 & 99.00018 & 0.203788 & 0.796032 \\
\hline & & (1.91016) & $(1.00653)$ & $(1.40145)$ \\
\hline \multicolumn{5}{|c|}{ Variance Decomposition of DBD: } \\
\hline Period & S.E. & DINF & DBD & DTAX \\
\hline \multirow[t]{2}{*}{1} & 4137.166 & 0.019010 & 99.98099 & 0.000000 \\
\hline & & $(0.73729)$ & $(0.73729)$ & $(0.00000)$ \\
\hline \multirow[t]{2}{*}{2} & 6651.230 & 0.029323 & 97.47761 & 2.493066 \\
\hline & & $(0.91272)$ & $(1.74231)$ & $(1.37830)$ \\
\hline \multirow[t]{2}{*}{3} & 7181.889 & 0.534918 & 96.92900 & 2.536085 \\
\hline & & $(1.48588)$ & $(2.44380)$ & $(1.91770)$ \\
\hline \multirow[t]{2}{*}{4} & 7262.073 & 1.048763 & 95.22223 & 3.729008 \\
\hline & & $(2.11016)$ & $(2.67727)$ & $(1.73894)$ \\
\hline \multirow[t]{2}{*}{5} & 7437.188 & 1.195773 & 91.19182 & 7.612403 \\
\hline & & $(2.40478)$ & (3.70898) & $(2.91622)$ \\
\hline \multirow[t]{2}{*}{6} & 7490.672 & 1.398762 & 90.39600 & 8.205242 \\
\hline & & $(2.60546)$ & $(4.08397)$ & $(3.44813)$ \\
\hline \multirow[t]{2}{*}{7} & 7635.006 & 1.349821 & 87.13256 & 11.51762 \\
\hline & & $(2.52452)$ & $(3.97720)$ & (3.36289) \\
\hline \multirow[t]{2}{*}{8} & 7984.658 & 1.244656 & 81.62389 & 17.13145 \\
\hline & & $(2.38808)$ & $(4.60014)$ & $(4.31098)$ \\
\hline \multirow[t]{2}{*}{9} & 8080.816 & 1.216991 & 81.18003 & 17.60298 \\
\hline & & $(2.38811)$ & (4.74039) & (4.47639) \\
\hline \multirow[t]{2}{*}{10} & 8114.502 & 1.244210 & 80.54844 & 18.20735 \\
\hline & & $(2.38058)$ & $(4.81981)$ & $(4.51506)$ \\
\hline
\end{tabular}

Yazarlar tarafından hesaplanmıştır

\begin{tabular}{|c|c|c|c|c|}
\hline \multicolumn{5}{|c|}{ Variance Decomposition of DTAX: } \\
\hline Period & S.E. & DINF & DBD & DTAX \\
\hline 1 & 2347.614 & 0.011569 & 12.18834 & 87.80009 \\
\hline & & $(0.54584)$ & $(4.31192)$ & (4.34704) \\
\hline 2 & 3068.934 & 0.264179 & 24.51311 & 75.22271 \\
\hline & & $(0.95234)$ & $(5.97984)$ & $(6.10893)$ \\
\hline 3 & 3286.755 & 0.481813 & 31.73009 & 67.78810 \\
\hline & & $(1.53903)$ & (6.70744) & $(6.82126)$ \\
\hline 4 & 3328.219 & 0.902781 & 31.08770 & 68.00952 \\
\hline & & $(1.87893)$ & $(6.69531)$ & $(6.77097)$ \\
\hline 5 & 3422.476 & 1.195457 & 30.83244 & 67.97210 \\
\hline & & $(2.10764)$ & $(6.63547)$ & $(6.73693)$ \\
\hline 6 & 3453.397 & 1.205329 & 31.75785 & 67.03682 \\
\hline & & $(2.15443)$ & $(6.21521)$ & $(6.33927)$ \\
\hline 7 & 3869.792 & 0.964394 & 35.04184 & 63.99377 \\
\hline & & $(1.77863)$ & $(6.71777)$ & $(6.73663)$ \\
\hline 8 & 4135.947 & 0.896625 & 37.12774 & 61.97564 \\
\hline & & $(1.74123)$ & $(7.14315)$ & (7.17667) \\
\hline 9 & 4161.648 & 0.961672 & 37.76315 & 61.27518 \\
\hline & & $(1.94659)$ & $(7.24912)$ & (7.26917) \\
\hline 10 & 4237.285 & 1.030059 & 37.14498 & 61.82496 \\
\hline & & $(2.05640)$ & (7.16168) & $(7.15673)$ \\
\hline
\end{tabular}

Yazarlar tarafından hesaplanmıştır 
Varyans ayrıştırma hesaplama bulgularının incelemesini üç durum için şu şekilde yapılabilmektedir:

İlk olarak bağımlı değişken aylık enflasyon oranı alındığında ve on veri dönemi/on ay dikkate alındığında enflasyondaki değişmenin büyük ölçüde yine enflasyon kaynaklı şoklar tarafinda açıklandığ 1 söylenebilmektedir. Bu durum enflasyonun kendini beslemesini yani ataleti ortaya koymaktadır. Zaman süresi içinde enflasyondan sonra enflasyondaki değişmeleri açıklama gücü en yüksek değişkenin vergi geliri olduğu görülmektedir.

İkinci olarak bağımlı değişken bütçe açığı alındığında bütçe açığındaki değişmelerin en fazla bütçe açığ 1 kaynaklı şoklar olduğunu görülmektedir. Ancak bu bulgu enflasyonun bağımlı değişken alındığı ve enflasyonist ataleti yansıtan hesaplama kadar güçlü değildir. Buna ek olarak, bütçe açıklarındaki değişimi açıklama gücü en yüksek ikinci değişkenin vergi gelirleri olduğu görülmekte ve vergi gelirlerinin açıklama gücü zaman dönemleri boyunca artmaktadır. Son olarak bağımlı değişken vergi gelirleri olarak alındığında yine en yüksek açıklama gücü vergi gelirlerinin kendisinden kaynaklı şoklardan olduğu ortaya çıkmaktadır. Vergi gelirlerindeki değişmeyi açıklama gücü en yüksek bağımsız değişkenin ise bütçe açıkları olduğu bulgusuna ulaşılmıştır.

Sonuç olarak her üç durumdan elde edilen bulguların Tablo 3 'te gösterilen nedensellik bulgularıyla uyumlu olduğu anlaşılmıştır. Bu durum aynı zamanda model bulgularının tutarlı olduğunu da göstermiştir.

Şekil 2: Etki-Tepki Analiz Bulguları Response to Cholesky One S.D. Innovations \pm 2 S.E.
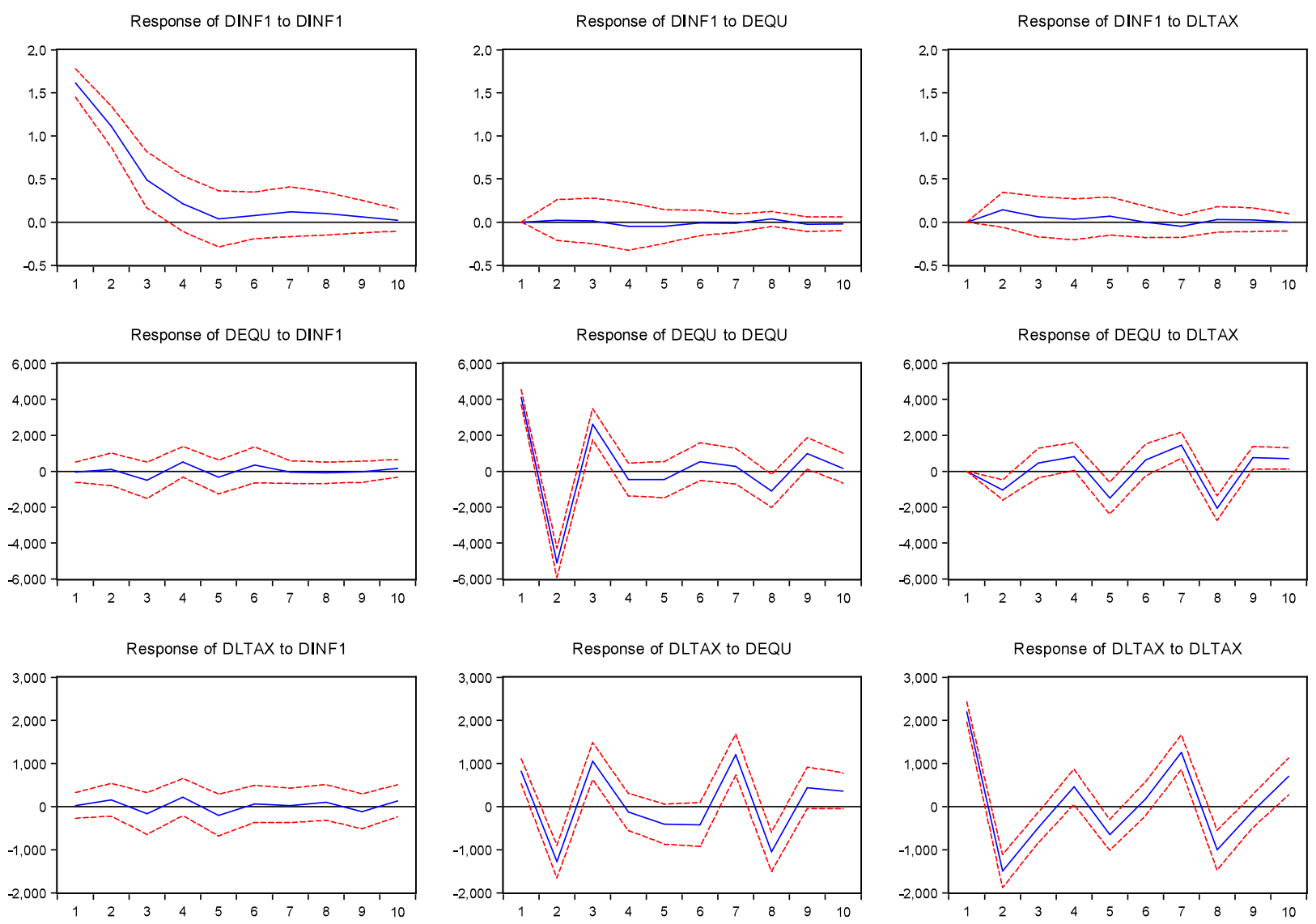

Şekil 2 kümesi etki tepki analiz sonuçlarını göstermektedir. Yine ele alınan her üç değişkenin sırayla bağımlı değişken olarak ele alındığı üç duruma göre etki tepki analiz 
bulguları açıklanabilir. Birinci durumda bağımlı değişken enflasyondur. Buna göre on zaman dönemi içinde şokların etkilerinin kaybolduğu yani bu şokların geçici şoklar olduğu ifade edilebilir. Ayrıca şoklara karşı bağımlı değişken dinamik tepkileri güven aralığı içinde olsa da sıfır eksenini içermeleri ve/veya kesmeleri modelinin etki tepki analizlerinin anlamsız olacağı biçimde tanımlanmıştır.

Çalışma bulguları enflasyon şoklarına enflasyonun tepkisinin pozitif ve zaman dilimleri için azaldığını göstermektedir. Bu bulgu varyans ayrıştırma hesaplaması bulgusuyla tutarlıdır ve ataleti desteklemektedir. Hem bütçe açığı kaynaklı hem de vergi geliri kaynaklı şoklara karşı enflasyon tepkisinin pozitif ve güven aralığı içinde olduğu görülürken sıfir ekseninin güven aralıkları içinde olması bulguların istatistiki olarak anlamsız çıkmasına yol açmıştır.

Bağımlı değişkenin bütçe açığı olduğu ikinci durumda bağımsız değişkenler kaynaklı şoklara karşı bütçe açığının tepkileri güven aralığı içinde olsa da istatistiki olarak anlamsız çıkmıştır. Bu bulgular nedensellik analizi ve varyans ayrıştırma hesaplaması bulgularıyla da tutarlılık göstermiştir.

Üçüncü durumda bağımlı değişken olarak vergi gelirleri alınmıştır. Üçüncü durumda da her üç değişkene karşı bağımlı değişkenler kaynaklı şoklara dinamik tepkileri güven aralığında ancak sıfır ekseni güven aralığg içinde olduğu için istatistiki olarak anlamsız çıkmıştır.

\section{Sonuç}

Enflasyon Türkiye ekonomisi açısından en önemli ekonomik sorunlar arasındadır. Bilhassa 90'lı yıllarda gerçekleşen kronikleşmiş yüksek enflasyon ekonominin sağlıklı işleyişini engellemiştir. Kronikleşen yüksek enflasyonda en önemli iki neden, tüketici harcamalarının genişletilmesi ve bütçe açıklarıdır. Bunun sonucunda ekonomi sık sık krizlerle karşılaşmıştır. Bu süreçte kamu açıkları enflasyonun nedeni olabileceği gibi, enflasyon da kamu bütçe dengesinin bozulmasına ve kamu gelirlerinde azalmaya neden olabilmektedir.

Enflasyon ve kamu bütçesi arasındaki bu karşılıklı etkileşim literatürde önemli bir yer edinmiştir ve bu bağlamda çalışmamız içinde referans olmuştur. Bu çalışmada enflasyon, bütçe açığı ve vergi gelirleri arasındaki karşılıklı etkileşim Türkiye ekonomisi açısından ele alınmıştır. Araştırma yöntemi olarak zaman serisi analizlerine başvurulmuş ve VAR modeline dayalı varyans hesaplama ve etki -tepki analizleri kullanılmıştır. VAR yöntemi uygulanmadan önce çalıșmada ele alınan değișkenlerin durağanlık sınamaları ADF ve PP testlerine göre yapılmış ve tüm değişkenlerin birinci sıra farkları alındıklarında durağan oldukları görülmüştür.

Durağanlık sınamalarından sonra korelasyon ve nedensellik ilişskileri incelenmiş ve iktisat teorisine uygun biçimde tüm değişkenler arasında nedensellik ilişkisinin olduğu görülmüştür. Nedensellik analizi sonuçları değişkenleri içsel ve dişsal değişken olarak ayırmaya gerek bırakmayan VAR modelinin çalışma açısından en uygun model olduğu sonucuna ulaşılmasına imkân sağlamıştır.

VAR modeline dayalı olarak hesaplanan Varyans ayrıştırma hesaplaması bulguları bir değişkenden kaynaklı şokların diğer değişkendeki değişmeyi açıklama gücünü vermektedir. Varyans ayrıştırma hesaplamasından elde ettiğimiz bulgular Türkiye'de enflasyonun en önemli sebebinin atalet yani kendi kendini besleme olduğu yönündeki literatürle uyumludur. Açıkçası enflasyon hedeflerini yakalamada karşılaşılan güçlükler ve başarısızlıklar neticesinde iktisadi birimlerin para politikası uygulayıcısı olan Merkez Bankasının hedeflerine güvenmemelerine ve kendi fiyatlama davranışlarında geçmiş enflasyonu referans almalarına yol açmıştır. $\mathrm{Bu}$ durum yani oluşan kredibilite kaybının enflasyonda belli bir düzeyde direnç oluşmasına yol açarak merkez bankası hedef patikasında sapmalara neden olduğu söylenebilir. 
Varyans ayrıştırma hesaplamasının iki önemli bulgusu vergilerin bütçe açıklarında değişmeyi etkilemede önemli bir açıklayıcı güç olmasının yanında bütçe açıklarının da vergilerde meydana gelen değișmeyi açıklayıcı güç olmasıdır. Bu sonuçlar vergi gelirleri ve bütçe açıkları arasındaki karşılıklı bağımlılığı bir kez daha ortaya koymuş ve nedensellik analizini desteklemiştir.

VAR modeline dayalı etki tepki analizlerinde ise bağımsız değişkenden kaynaklı şokları karşısında bağımlı değişkenin gösterdiği tepki tahmin edilmeye çalışılmaktadır. Diğer yandan bu tepkinin istatistiki olarak anlamlı olabilmesi için sıfır çizgisinin güven aralıkları içerisinde veya ona teğet olmaması gerekmektedir. Elde edilen bulgulara göre enflasyonun kendi kendini beslediği olgusu yani atalet koşulu bir kez daha karşımıza çıkmıştır. Diğer yandan enflasyonun kendinden kaynaklı şoklara gösterdiği tepki dışında diğer değişkenlerin şoklara verdikleri tepki istatistiki olarak anlamsız çıkmıştır. Bu bulgular beklentilerle uyumsuz olsa da tahmin dönemi ve/veya modelde yer alan değişkenlerin enflasyonu açıklama gücündeki düşüklüklerden ya da yetersizliklerden kaynaklanmış olabilir. Ancak değişkenler arasında karşılıklı etkileşimin varlığı nedensellik analizi çerçevesinde yukarıda ifade edildiği gibi sorgulanmış olup karşılıklı bağımlılığın varlığı tahmin edilmiştir. Nedensellik analizi bulgularının iktisat teorisiyle uyumlu olması çalışmanın tutarlılığı açısından önemli bir sonuç olduğu ifade edilebilmektedir.

Sonuç olarak çalışmada vergi gelirlerini de içerecek biçimde enflasyon ve kamu kesimi ilişkisi ortaya konmaya çalışılmış ve elde edilen sonuçlar ile literatür araştırmasının uyumlu olduğu gözlemlenmiştir. Bu araştırmalar neticesinde enflasyon, vergi geliri ve bütçe açıkları arasındaki ilişkilere dayalı üç önemli tahmin yapılması olanaklı hale gelmiştir. Bunlardan ilki enflasyon, vergi gelirleri ve bütçe açıkları arasında karşılıklı bir etkileşimin olduğu bulgusudur. İkincisi ise enflasyonist ataletin enflasyondaki değişmeleri en fazla açıklayan olgu olduğudur. Son olarak ta enflasyonun aynı zamanda vergi gelirlerinde aşınmaya neden olduğu olgusudur. Bu olguda Tanzi-Olivera etkisi ile uyumluluğunu ortaya koymuştur. 


\section{Kaynakça}

Abdioğlu, Z., Terzi, H. (2009), "Enflasyon ve Bütçe Açıkları İlişkisi: Tanzi ve Patinkin Etkisi”,, Atatürk Üniversitesi İktisadi ve İdari Bilimler Dergisi, 23:2, 195-211.

Anusic, Z. (1994), "Budget Deficit and Inflation", Croatian Economic Survey, 21-36.

Alper, F. Ö. (2018), “Türkiye'de Bütçe Açığı, Para Arzı ve Enflasyon Arasındaki İlişkinin İncelenmesi: 1971-2016 Business and Dönemi”, Economics Research Journal, 9:4, 799-810.

Altunöz, U. (2018), "Enflasyon ve Bütçe Açıkları Arasındaki İlişki Bağlamında Olivera-

Tanzi ve Patinkin Etkisinin Türkiye'de Geçerliliği”, Vergi Dünyası Dergisi, 438, 21-33.

Ataç, B. (2016) Maliye Politikası, Ankara: Turhan Kitabevi.

Bayır, M., Güvenoğlu, H. (2020), "The Analysıs of Relatıonshıp Between The Money Supply, Budget Deficit And Inflation in Turkey: 2009-2019”, ICOAEF'20,VII International Conference on Applied Economics and Finance \& EXTENDED WITH SOCIAL SCIENCES), 186-197.

Bayrak, M. ve Kanca, O. (2013), "Türkiye'de Kamu Kesimi Açıklarının Nedenleri ve Fiyatlar Genel Düzeyi Üzerindeki Etkileri”, İ.Ü. Siyasal Bilgiler Fakültesi Dergisi, 48:1, 91-111.

Bedir, S., Tural, A. (2014), "Bütçe Açı̆̆ı ve Enflasyon: Türkiye İçin Bir Sınır Testi Yaklaşımı”, International Conference on Eurasian Economies, 915 , 1-9.

Beşer, M. K. (2007). Boostrapt VAR modeller ve Türkiye'de Tanzi etkisi. Zonguldak Karaelmas Üniversitesi Sosyal Bilimler Dergisi, 3(6), 89- 108.

Çavuşoğlu, T. (2005). Vergi gelirleri ve kamu harcamaları açısından enflasyon: Tanzi ve ters Tanzi etkileri. Gazi Üniversitesi İktisadi ve İdari Bilimler Fakültesi Dergisi, 7(3), 35-52.

Chukwuani, V. N., Egiyi, M. A. (2020), "Nexus between Budget Deficit and Inflation: GrangerCausality Test Approach", International Journal of Academic Accounting, Finance \& Management Research (IJAAFMR), 4:10, 19-23.

Dinler, Z. (2019), İktisada Giriş, Bursa: Ekin Basım Yayım Dağıtım.

Edizdoğan, N., Çetinkaya, Ö. (2019), Kamu Bütçesi, Bursa: Ekin Basım Yayım Dağıtım.

Erdem, M.; Şenyüz, D.; Tatlığlu, İ. (2012), Kamu Maliyesi, Bursa: Ekin Basım Yayım Dağıtım.

Erdil Şahin, B. (2019), “Analysis of The Relationship Between Inflation, Budget Deficit and Money Supply in Turkey by ARDL Approach: 1980-2017”, Journal of Life Economics, 6:3, 297-306.

Erdoğan, S. ve Erdoğan, A. (2018). Türkiye'de Tanzi ve Patinkin etkilerinin VAR yöntemiyle analizi (2006 - 2017). Aksaray Üniversitesi İktisadi ve İdari Bilimler Fakültesi Dergisi, 10(1), $1-10$.

Erkam, S., Çetinkaya, M. (2014), "Budget Deficits and Inflation: Evidence from Turkey", The Macrotheme Review 3:8, 12-22.

Feyzioğlu, B. (1997), İktidar Virüsü (Ülke Sorunlarının Saydam Analizi), İstanbul: Çağdaş.

Georgantopoulos, A. G.; Tsamis, A. D. (2011), "The Macroeconomic Effects of Budget Deficits in Greece: A VAR-VECM Approach", International Research Journal of Finance and Economics, 79, 156-166. 
Ishaq, T., Mohsin, H. M. (2015), "Deficits and inflation; Are monetary and financial institutions worthy to consider or not?", Borsa İstanbul Review, 15:3, 180-191.

İpek, E., Akar, S. (2016), "Bütçe Açı̆̆1 ve Enflasyon Arasındaki İlişki: Türkiye için Ampirik Bir Analiz”, Marmara Üniversitesi İktisadi ve İdari Bilimler Dergisi, 38:2, 167-189.

Kaya, M., Öz, E. (2016), "Enflasyon, Bütçe Açığı ve Para Arzı İlişkisinin Türkiye Ekonomisi Açısından Değerlendirilmesi: 1980-2014 Dönemi", Yönetim ve Ekonomi: Celal Bayar Üniversitesi İktisadi ve İdari Bilimler Fakültesi Dergisi, 23:3, 639-651.

Kazdaglı, Hüseyin (1996), "Türkiye Cumhuriyeti Merkez Bankası'nın Kuruluş Tarihçesi ve 1934- 1938 Dönemindeki Para Politikasının VAR Yöntemiyle Analizi," Hacettepe Üniversitesi Iktisadi ve Idari Bilimler Fakü/tesi Dergisi, Cilt.14, SaY1,2: 35-52.

Lozano, I. (2008), "Budget Deficit, Money Growth and Inflation: Evidence from the Colombian Case", Borradores de Economia, No:537, 1-24.

Oktayer, A. (2010), “Türkiye'de Bütçe Açığı, Para Arzı ve Enflasyon İlişkisi”, Maliye Dergisi, Say1: $158,431-447$.

Olivera, J.H.G. (1967), 'Money, Prices and Fiscal Lags: A Note on the Dynamics of Inflation', Banca nazionale del lavaro, Vol: 20, September 1967.

Oruç, E. (2016), "Bütçe Açıkları Enflasyonist Etkiye Sahip Midir? Türkiye Üzerine Uzun Dönemli Analiz", AİBÜ Sosyal Bilimler Enstitüsü Dergisi, 16:1, 1-21.

ÖZGEN, F.B., GÜLOĞLU, B., “Türkiye'de İç Borçların İktisadi Etkilerinin VAR Tekniğiyle Analizi”, METU Studies in Development, s. 101-103, 31 (Haziran), 2004.

Özbilen, Ş. (1999) Maliye Politikası, Bursa: Ezgi Kitabevi.

Patience, A. I., Augustine, O. O. (2008), Deficit Financing and its Inflationary Impact on Developing Economies: Nigerian Economy in Perspective, Journal of Financial Management and Analysis, 21:1, 58-68.

Pınar, A. (2017) Maliye Politikası, Ankara: Turhan Kitabevi.

Sağlam, M., Uğurlu, E. (2013), "Kamu Açıkları, Parasal Büyüme ve Enflasyon İlişkisi: Türkiye Örneği (1983-2008)", Finans Politik ve Ekonomik Yorumlar, 50:576, 71-83.

Samirkaş, M. (2014), "Effects of Budget Deficits on Inflation, Economic Growth and Interest Rates: Applications of Turkey in 1980-2013 Period", Journal of Economics and Development Studies, 2: 4, 203-210.

Solomon, M., Wet, W. A. (2004), "The Effect of a Budget Deficit on Inflation: The Case of Tanzania", South African Journal of Economic and Management Science, 7:1, 100-116.

Tiwari, A. K., Bolat, S.; Koçbulut, Ö. (2015), "Revisit the Budget Deficits and Inflation: Evidence fromTime and Frequency Domain Analyses", Theoretical Economics Letters, 5, 357369.

Somel, C. (2014) Makro İktisada Giriş, İstanbul: Yordam Kitap.

Şener, O. (2016) Kamu Ekonomisi, İstanbul: Beta Basım.

Tanzi, V. (1978), 'Inflation, Real Tax Revenue, and the Case for Inflationary Finance: Theory with an Application to Argentina', IMF Staff Papers, Vol:25, pp.417-451 
Zonuzi, J. M., Pourvaladi, M. S. H.; Faraji, N. (2011), "The Relationship between Budget Deficit and Inflation in Iran", Iranian Economic Review, 15:28, 117-133. 